\begin{tabular}{l|l}
\hline SISTEMA \\
ELETRONICO \\
DE REVISTAS \\
SER I UfPR
\end{tabular}

\title{
As mudanças climáticas no Twitter: a ascendência da mídia e da política
}

\section{Climate Change in Twitter: The Prevalence of Media and Politics}

\author{
Alice Dutra BALBE ${ }^{1 *}$, Anabela CARVALHO ${ }^{2}$ \\ ${ }^{1}$ Programa Doutoral em Ciências da Comunicação, Universidade do Minho, Braga, Portugal. \\ ${ }^{2}$ Departamento de Ciências da Comunicação, Universidade do Minho, Braga, Portugal \\ *E-mail de contato: alicedb.jornal@gmail.com
}

Artigo recebido em 30 de outubro de 2016, versão final aceita em 1 de fevereiro de 2017.

RESUMO: $\quad$ A $21^{\text {a }}$ Conferência das Partes (COP21) da Convenção-Quadro das Nações Unidas sobre Mudanças no Clima foi apontada como a mais promissora reunião para um acordo global de combate aos efeitos das mudanças climáticas e redução da emissão de gases de efeito estufa. Este artigo analisa a comunicação sobre as mudanças climáticas no ambiente online durante o período da Conferência. Os temas debatidos nas redes sociais são suscetíveis a afetar o debate de forma ampla e trazem importantes informações a respeito da opinião pública e de percepções sobre as mudanças climáticas (Williams et al., 2015). Para este fim, o trabalho foca-se na popular rede social Twitter, que tem sido apontada como um termômetro da percepção pública (Brown \& Wake, 2015). O Twitter tem mais de 310 milhões de utilizadores ativos por mês, dos quais $79 \%$ estão fora dos Estados Unidos da América, o que possibilita analisar outros contextos e fomentar a investigação em idiomas sub investigados, como o espanhol e o português. Lança-se um primeiro olhar sobre os usos e conteúdos publicados no Twitter nas línguas mencionadas visando responder às seguintes questões: Que tipo de conteúdos são mais populares no Twitter sobre mudanças climáticas? Qual a linguagem (palavras e nomes) utilizada para se debater o tema? Até que ponto é que a mídia tradicional é referência relevante no contexto da comunicação sobre as mudanças climáticas na rede social? Quem são os atores que formam esta rede e quais são os mais influentes? Conclui-se, entre outros aspectos, que entre os atores da rede se destacam diversos políticos e que a mídia é referência importante de informação nesta rede social. Nos dados em língua portuguesa, constatou-se um nível de atividade muito elevado dos cidadãos, que dominaram a produção de conteúdos sobre a COP21.

Palavras-chave: mudanças climáticas; comunicação; redes sociais; Twitter.

ABSTRACT: The 21st Conference of Parties (COP21) of the United Nations Framework Convention on Climate Change was identified as the most promising summit for a global agreement aiming to combat the effects of climate change and to reduce emissions of greenhouse gases. This article analyses online communications about climate change during the Conference. The subjects discussed in social networks are likely to affect public debates and provide important information regarding public opinion and perceptions of climate change (Williams et 
al., 2015). This paper focuses on the popular social network Twitter, which has been considered a barometer of public perception (Brown \& Wake, 2015). Twitter has more than 310 million active users per month, of which $79 \%$ are outside the United States, allowing for analyses of different linguistic contexts, namely underresearched ones, such as Spanish and Portuguese. The study provides an overview of Twitter uses and content in those languages and aims to answer the following research questions: Which type of content about climate change is most popular in Twitter? What kind of language (words and names) is used to discuss this issue? To what extent are traditional media a relevant reference in climate change communication in this social medium? Who are the actors that compose this social network and who are the most influential ones? We conclude, among other things, that several politicians stand out as some the most influential actors and that the media are important sources of information in this social network. In the Portuguese data, the study found a very high level of activity of citizens, who dominated the production of content on COP21.

Keywords: climate change; communication; social media; Twitter.

\section{Introdução}

A utilização da internet como fonte de informação sobre as mudanças climáticas tem crescido substancialmente e já supera o rádio em alguns países (Schäfer \& Schlichting, 2014). Nos últimos dez anos, o surgimento de novas plataformas e sites de redes sociais tem transformado a comunicação. Considera-se que os conteúdos das redes sociais contêm indicativos acerca da opinião pública e que podem ter um impacto significativo sobre as percepções e atitudes dos utilizadores (Williams et al., 2015).

A revisão de literatura mostra que a investigação sobre a comunicação das mudanças climáticas no contexto das redes sociais é ainda incipiente e debruça-se principalmente sobre conteúdos em língua inglesa. Com este artigo, busca-se fomentar a investigação nos idiomas espanhol e português de modo a abranger contextos distintos.
Na América Latina, segundo o Pew Research Center ${ }^{1}, 74 \%$ da população considera as mudanças climáticas como um problema muito sério e $77 \%$ acreditam que já afeta as pessoas agora. A média da população de latino-americanos que se declarou preocupada foi de $61 \%$. A média global ficou entre os $54 \%$, valor correspondente também a preocupação dos europeus. Na Europa, o país que revelou uma maior preocupação foi a Espanha, com percentagem de $59 \%$. Diante da realização recente da $21^{\mathrm{a}}$ Conferência das Partes (COP21), da Convenção-Quadro das Nações Unidas sobre Mudanças no Clima, utiliza-se este espaço para analisar a comunicação na rede social Twitter sobre as mudanças climáticas e os atores que criam a rede de comunicação sobre o tema. O Twitter é uma rede social digital e servidor de microblogging que permite publicações curtas, chamadas tweets, com texto de até 140 caracteres. A rede social foi criada em 2006 e possui 310 milhões de utilizadores ativos $^{2}$ por mês (Twitter, março de 2016) ${ }^{3}$.

\footnotetext{
${ }^{1}$ Disponível em: <http://www.pewglobal.org/2015/11/05/global-concern-about-climate-change-broad-support-for-limiting-emissions/>. Acesso em: ago. 2016.

${ }^{2}$ Disponível em: https://about.twitter.com/company. Acessado em: ago. 2016. No qual refere-se que 79\% dos utilizadores cadastrados estão fora dos Estados Unidos da América.

${ }^{3}$ As relações na rede social não implicam em reciprocidade ou relação de "amizade" para receber as publicações. Pode-se "seguir" sem necessariamente "estar sendo seguido" e as mensagens são públicas por padrão, sendo que é possível alterar esta configuração. Os utilizadores são identificados através do @utilizador (símbolo@, seguido do nome de utilizador). A rede social incita o utilizador a responder à pergunta “o que
} 
Esta investigação procura responder às seguintes questões: Que tipo de conteúdos são mais populares no Twitter sobre o tema? Qual a linguagem (palavras, nomes) utilizada para se debater o tema? Até que ponto a mídia tradicional é referência relevante no contexto da comunicação das mudanças climáticas na rede social? Quem são os atores que formam esta rede e quais são os mais influentes?

$\mathrm{O}$ artigo parte de uma breve revisão da literatura sobre os usos das redes sociais e a comunicação das mudanças climáticas, apresenta em seguida a metodologia adotada e centra-se depois na análise dos dados e sua discussão.

\section{Breve revisão da literatura}

A instantaneidade proporcionada pela internet e os usos crescentes de sites redes sociais destacam a rede social Twitter como um termômetro da percepção pública relativamente a questões da atualidade (Brown \& Wake, 2015). Caracterizado como um espaço de atualização de informação, partilha de notícias, difusão de informação e também um espaço de interação social (Recuero, 2009; Kwak et al., 2010; Segerberg \& Bennett, 2011; Theocharis et al., 2014), o Twitter é o campo de pesquisa escolhido para este estudo. As mensagens publicadas na rede, embora curtas, fornecem uma variedade de informações para pesquisa.

A comunicação no Twitter vem sendo investigada nos últimos anos com análises do retweet como uma prática conversacional (Boyd et al., 2010), do uso da rede como uma forma de comunicação em situações de desastres (Takahashi et al., 2015), de mobilização para ações nas ruas (Theocharis et al.,
2014), e da atuação de organizações não-governamentais e associações (Merry, 2014), entre outros aspectos.

O papel dos agentes que usam o Twitter é também uma questão de interesse, pois são estes atores que formam a rede. Por exemplo, Cha et al. (2010) investigaram a relação de influência dos utilizadores sobre os outros dentro da rede e Rudat et al. (2014) mostraram que a rede de seguidores tem impacto no conteúdo produzido pelos utilizadores. $\mathrm{O}$ estudo de atores inclui os usos das redes sociais para a comunicação política em variadas perspectivas, como as publicações para campanhas políticas e as estratégias utilizadas (Amaral et al., 2016) e a participação e o envolvimento da população com a política (Bekafigo \& McBride, 2013). Hajibagheri e Sukthankar (2014) estudaram a relação entre posicionamentos políticos e a comunicação das mudanças climáticas, e como os partidos políticos influenciam nos próprios termos utilizados nas discussões e na divulgação das informações sobre as mudanças climáticas nas redes sociais.

A investigação sobre as mudanças climáticas nas redes sociais é recente e ainda limitada, apesar do potencial e do vasto campo de informação que as redes sociais proporcionam (O'Neill \& Boykoff, 2011; Auer et al., 2014). Sabe-se que a realização de eventos internacionais, as agendas intergovernamentais, as publicações de lideranças políticas e/ou pessoas famosas e os eventos meteorológicos extremos proporcionam um aumento nas abordagens não só na mídia tradicional como também nas referências ao tema nas redes sociais (Kirilenko \& Stepchenkova, 2014; Pearce et al., 2014; Cody et al., 2015).

está acontecendo?". Cada publicação é considerada original, mas existem recursos para o compartilhamento, o chamado retweeting, conhecido como RT. Outra forma de partilhar uma publicação é citar o autor, como por exemplo, via @utilizador seguido da mensagem. 
Em grande parte dos estudos relacionados às mudanças climáticas a mídia tem sido apontada como a principal fonte de informação nas redes sociais. Kirilenko et al. (2015) detectaram que nos Estados Unidos da América 48\% dos artigos publicados relacionados às "mudanças climáticas" e "aquecimento global" eram provenientes de somente dois jornais. Além da mídia, os tweets eram muitas vezes de associações, empresas, organizações não-governamentais e pouco do público em geral. Mesmo assim, foi possível identificar que o público percebe as variações do clima e partilha essas informações.

A análise de sentimento das publicações sobre clima no Twitter aponta para uma relação negativa associada aos termos (Hansen et al., 2011; Cody et al., 2015). Na maioria dos dados analisados por Cody et al. (2015) a palavra "clima" é associada a "negação" e repercussões negativas quanto aos desastres naturais. As discussões no ambiente online vinculadas às mudanças climáticas estão muitas vezes relacionadas com o estado do tempo no dia e são mais intensas quando há ocorrências meteorológicas mais severas ou frequentes, como tempestades, furacões e tornados. A associação destes eventos extremos com as mudanças climáticas tem sido registrada desde 2011, após a passagem do furacão Irene, que atingiu os Estados Unidos da América (Cody et al., 2015, p. 11). Por outro lado, estas discussões são mais concentradas entre os ativistas do que entre céticos e negadores das mudanças climáticas, ou seja, há mais conversação entre os que se declaram ativistas, como participantes de organizações ambientais, que acreditam nas mudanças climáticas do que entre os negadores. $\mathrm{O}$ uso constante de termos como "ciência" e "cientistas" também demonstra algum consenso sobre o estado do conhecimento sobre a questão.
A tendência de compartilhar informação negativa no Twitter tem estado relacionada com a partilha de notícias (Hansen et al., 2011). Em uma análise envolvendo três tipos de amostras, nas quais a maior parte continha notícias, percebeu-se que se a notícia tiver conteúdo de teor negativo terá mais chance de ser retweetada, inclusive na amostra relacionada à COP15. No entanto, a análise de sentimento descobriu que quando se trata da interação entre os utilizadores, as informações positivas se propagam mais.

O Twitter foi analisado, no contexto da realização da COP15, como um mecanismo de organização de ações coletivas, como é o caso dos protestos/ manifestações (Segerberg \& Bennett, 2011). Concluiu-se que o Twitter tem um papel de agente (ou actante) na rede, que a tecnologia organiza os mecanismos e os atores moldam as estruturas de ligação. Entretanto, este espaço envolve uma negociação entre as ações individuais e coletivas, na junção de interesses em comum, como por exemplo através do uso de hashtags.

As hashtags são entendidas como uma tentativa de unir pessoas com interesses em comum no debate e, no caso das mudanças climáticas, tornar o fenômeno mais tangível, na definição de Pearce et al. (2014, p. 9): "In general, the use of these hashtags represented attempts to (re-)establish publics with particular interests connected with the debate, and to make the socially intangible phenomenon of climate change more tangible". Através da análise das hashtags utilizadas nos tweets acerca da divulgação do $5^{\circ}$ relatório do Painel Intergovernamental sobre as Mudanças Climáticas (IPCC), os conteúdos puderam ser classificados entre: ciência, campanha política, discussão geográfica e preocupações sociais e novas tecnologias. Williams et al. (2015) fizeram uma análise de cinco hashtags relacionadas com "climate change", a partir de uma seleção de 100 
tweets capturados. Os resultados apontaram para um elevado número de publicações referentes ao conteúdo da mídia e um consenso científico sobre a influência humana nas mudanças climáticas. Os investigadores referem que o impacto das redes sociais pode ser maior em países que têm maiores níveis de acesso à internet; por outro lado, aqueles que têm acesso à internet em países em que a média de acesso é baixa são mais suscetíveis a se tornarem líderes de opinião (Williams et al., 2015, p. 136).

A partir disto, percebe-se que a análise através de hashtags é bastante utilizada em análises de redes sociais e tem se mostrado eficiente para identificar publicações sobre tópicos de interesse. Diversos métodos de análise têm sido utilizados para administrar o grande volume de dados que são gerados através dos usos das redes sociais. Nesta investigação, pretende-se identificar quem são os atores que formam a rede, que tipo de mensagens são partilhadas numa amostra temporal envolvendo a realização da $21^{\mathrm{a}}$ Conferência das Partes e quais são as referências/fontes de informação utilizadas.

\section{Metodologia}

Para este trabalho, usou-se o web service do Twitter em conjunto com a ferramenta Netlytic ${ }^{4}$ para capturar e armazenar os tweets de interesse através dos termos selecionados (i.e., \#COP21 e COP21). Em seguida, recorrendo a ferramentas computacionais para mineração e análise de dados suportadas por linguagens de programação, nomeadamente Java e R, os dados previamente capturados foram sane- ados (e.g., eliminados erros e emojis ${ }^{5}$ ) e posteriormente processados, o que possibilitou uma análise eficiente do grande número de tweets resultantes.

Foram coletadas as publicações na rede social Twitter no período de realização da $21^{\mathrm{a}}$ Conferência das Partes da Convenção-Quadro das Nações Unidas sobre Mudanças no Clima, de 30 de novembro a 13 de dezembro de 2015, com referência ao termo COP21 e \#COP21, nos idiomas espanhol e português. O total de tweets coletados foi de 295.750. Optou-se pela delimitação linguística pois, apesar do elevado número de falantes dos dois idiomas, a maior parte das pesquisas cinge-se a contextos anglófonos.

A análise dos dados baseia-se na abordagem proposta por Herring (2009), que expande a noção de análise de conteúdo restrita e aplica métodos tradicionais e não-tradicionais na análise na web. Herring (2009) atribui a denominação WebCA (Web Content Analysis) para definir o paradigma de análise de conteúdo para a web que considera o conteúdo como os vários tipos de informações. Assim, parte-se dos preceitos da análise de conteúdo tradicional, com características objetivas e sistemáticas, e inclui-se conteúdos com múltiplas funções que caracterizam o conteúdo da web, como links, imagens, textos e hyperlinks, "all of which can communicate meaning" (Herring, 2009, p. 11).

Para a análise dos tweets, foram realizadas observações preliminares através da ferramenta gratuita de concordâncias e análise de texto AntConc ${ }^{6}$ para identificar as palavras mais recorrentes nos tweets, formando uma lista inicial de 100 palavras (wordlist) em cada idioma.

\footnotetext{
${ }^{4}<$ https://netlytic.org/>.

${ }^{5} \mathrm{O}$ emoji é um ideograma usado em mensagens eletrônicas e páginas da web, também conhecido como emoticon e smiley; inclui diversas imagens desde expressões faciais, animais, gestos e estado do tempo.

${ }^{6} \mathrm{http}: / /$ www.laurenceanthony.net/software.html
} 
Para a análise das mensagens mais partilhadas organizou-se um ranking dos 100 tweets mais partilhados, tendo como pressuposto que as mensagens mais disseminadas e retweetadas contêm características de relevância para os utilizadores da rede social. Os retweets dão valor ao conteúdo publicado (Cha et al., 2010), definindo as mensagens mais populares na rede. Foram identificadas as características das publicações com análises de multimodalidade (artifícios usados: links, fotos, vídeos) e referências/fontes de informação, bem como realizada uma análise do conteúdo das 25 publicações mais partilhadas (que incluem as partilhas automáticas RT e reprodução da mesma mensagem).

Devido ao grande volume de dados, primeiramente se definiu os critérios de análise dos atores que formam a rede de publicações sobre o tópico "COP21", detendo-se na identificação de quem publica mais e quem são os utilizadores mais citados no período, formando assim dois rankings dos "100 mais". A identificação dos 100 perfis dos utilizadores mais ativos na rede social no período busca distinguir os perfis que mais publicaram conteúdo, incluindo RTs. Os 100 perfis mais mencionados na rede social incluem conversações entre utilizadores e partilha de publicações (os RTs), o que significa que estes perfis são potencialmente influentes. Aqui busca-se levantar pistas sobre o que se fala na rede e quais/quem são as referências utilizadas, através da categorização dos utilizadores. $\mathrm{Na}$ análise da influência no Twitter alguns autores correlacionam o número de seguidores, as mensagens mais retweetadas do perfil e o número de menções (Cha et al., 2010). Nesta pesquisa considera-se as referências feitas aos perfis, ou seja, os que são mais citados.

Os utilizadores foram classificados com base nas definições que são apresentadas nos perfis dos @ utilizadores, conforme a Tabela 1. Formaram-se seis grupos: mídia, governo e classe política, cidadãos, organizações cívicas, organizações intergovernamentais e empresas, com subcategorias conforme a tipologia específica. A "mídia" abrange empresas de mídia (os veículos de comunicação), jornalistas e portais de informação (blogs, páginas que se definem como "jornalismo independente/alternativo" e páginas não oficiais de divulgação, por exemplo, páginas que apenas replicam conteúdos oriundos de outros meios, ou seja, que não produzem conteúdo e replicam de outros). A categoria "governo e classe política" é dividida em subcategorias como órgãos governamentais (inclui vários tipos de páginas oficiais), representantes políticos (pessoas com cargos públicos e políticos), e partidos políticos e membros/apoiantes dos partidos. $\mathrm{Na}$ categoria relativa aos "cidadãos", nos casos em que foi possível identificar "ativistas", eles foram agrupados em subcategoria com o mesmo nome. Por sua vez, a subcategoria "anônimos" enquadra pessoas e perfis sem qualquer referência ou identificação (utilizadores sem descrição no perfil e números do nome de perfil, etc.) e "outros" agrega utilizadores com diferentes profissões, como estudantes de diversas áreas, professores, escritores, etc. As “organizações cívicas” incluem organizações não-governamentais e associações (grupos de ambientalistas e de outras áreas sociais). As “organizações intergovernamentais" não foram discriminadas em subcategorias por não se justificar distinções. As "empresas" foram colocadas como um grupo à parte porque têm objetivos distintos; são membros da sociedade civil que, no entanto, têm poderes e interesses diferentes, mas particulares. A categoria inclui empresas e empresários. 
TABELA 1 - Classificação de atores da rede.

\begin{tabular}{|c|c|}
\hline Categorias & Subcategorias \\
\hline Mídia & Órgãos/Empresas, Portais, Jornalistas \\
\hline $\begin{array}{l}\text { Governo e classe } \\
\text { política }\end{array}$ & $\begin{array}{l}\text { Órgãos de governo, Representantes } \\
\text { políticos, Partidos políticos e integrantes }\end{array}$ \\
\hline $\begin{array}{l}\text { Organizações } \\
\text { intergovernamentais }\end{array}$ & Organizações intergovernamentais \\
\hline Grupos cívicos & $\begin{array}{l}\text { Organizações não-governamentais, } \\
\text { Grupos e Associações }\end{array}$ \\
\hline Cidadãos & Ativistas, Anônimos, Outros \\
\hline Empresas & Empresas e Empresários \\
\hline
\end{tabular}

\section{Análises e discussão}

Esta seção apresenta os vários tipos de análises realizadas e, no final, enfatiza a mídia e a política, domínios identificados como particularmente importantes.

\subsection{Dimensões de análise}

Apresenta-se abaixo as várias dimensões analisadas no material coletado, nomeadamente o volume de publicações, a linguagem utilizada, as menções de países e nacionalidades, o nível de atividade dos atores sociais, a sua influência, a conectividade e os recursos visuais utilizados nas publicações, e a popularidade das publicações.

\subsubsection{Volume de publicações}

O volume de conteúdo em espanhol é bastante superior ao volume em português. No período da COP21, foram capturados 263.391 tweets em espanhol e 32.359 em português contendo referências ao termo "COP21". Os tweets em português correspondem a $10,94 \%$ do total das publicações coletadas.
Observa-se que a maior parte dos tweets utiliza a hashtag \#COP21 (211.157 em espanhol e 13.684 em português, totalizando 224.841); os demais fazem referência à COP21 na mensagem de texto publicada. A preferência pelo uso de hashtag vai ao encontro do que muitos autores referem sobre a formação de "comunidades" ao utilizarem-se termos em comum (e.g. Segerberg \& Bennett, 2011; Pearce et al., 2014; Williams et al., 2015). Identifica-se também que do total de publicações que utilizaram o termo "COP21" na língua espanhola, menos de um terço dos tweets é de texto original, sendo a maior parte partilha via RT. Em língua portuguesa, mais da metade dos tweets é texto original.

A movimentação de publicações variou ao longo da Conferência, tendo como ápice o primeiro dia, 30 de novembro de 2015 (chegando a ultrapassar os 58 mil tweets), e o penúltimo dia, 12 de dezembro (quase 28 mil tweets), do mesmo ano. É possível verificar na Figura 1 os índices das publicações como também observar a distribuição de publicação dos utilizadores. Ressalta-se que o adiamento da aprovação final do acordo e a expectativa para a conclusão suscitaram maior volume de publicações do que o próprio encerramento da Conferência. $\mathrm{O}$ volume de publicações no primeiro dia pode estar ligado à presença na $\mathrm{COP}$ de chefes de Estado e de governo, o que gerou uma grande visibilidade midiática (Brüggemann, 2015; $\mathrm{CJR}^{7}$, 2015; Nivela ${ }^{8}$, 2016).

\subsubsection{Linguagem}

A linguagem empregada relativamente às mudanças climáticas pode estar associada a significações específicas (cf. Whitmarsh, 2009) e as de-

\footnotetext{
${ }^{7}$ https://www.cjr.org/index.php

${ }^{8} \mathrm{http}: / /$ www.nivela.org/about/en
} 


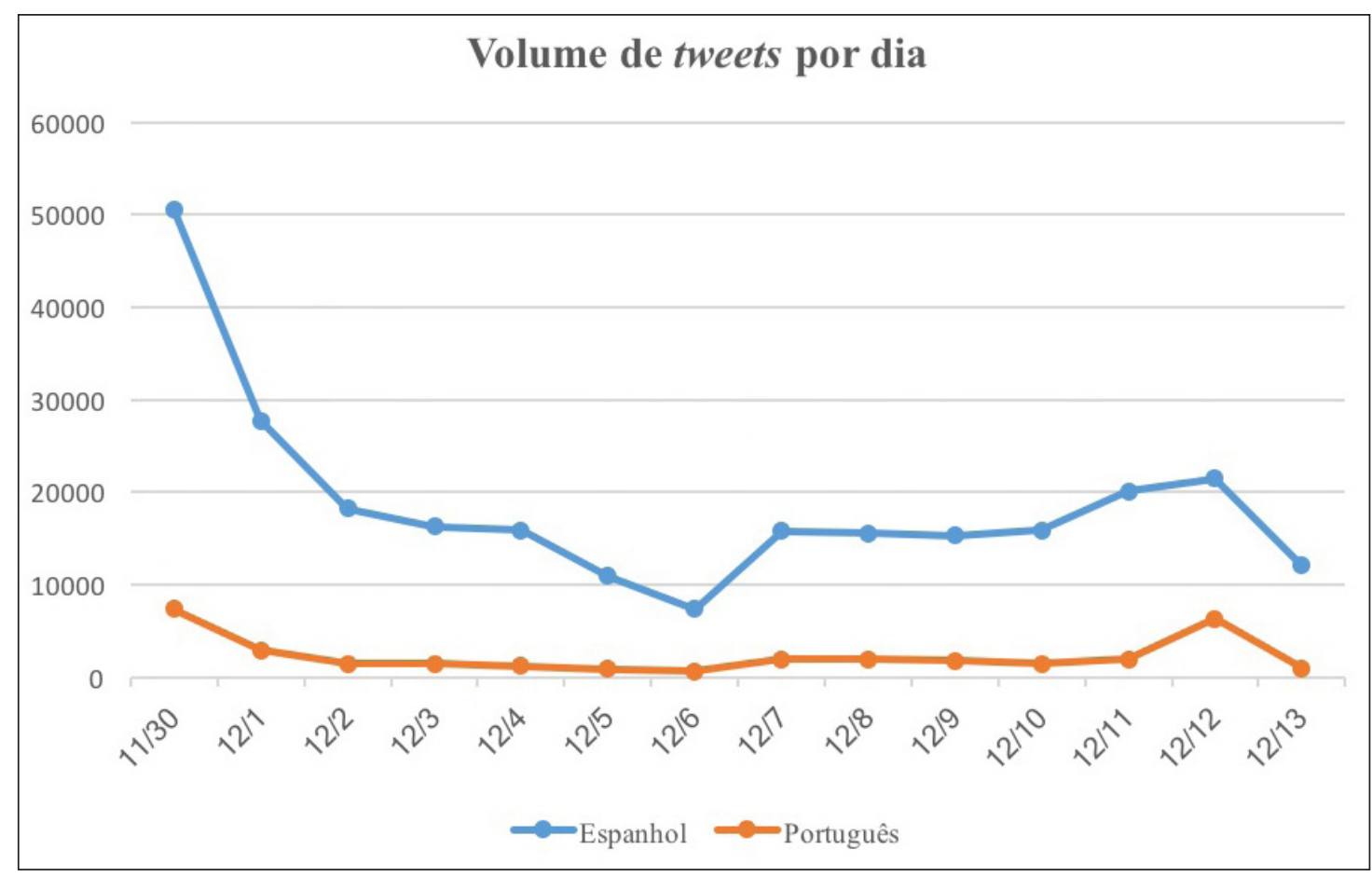

FIGURA 1 - Distribuição das publicações ao longo da COP21.

signações dadas a esta Conferência podem fornecer indicadores de tendências de perspectivação por parte de um público amplo. Desta forma, buscou-se nas publicações informações sobre a utilização de outros termos como sinônimos de "Conferência das Partes da Convenção-Quadro das Nações Unidas sobre Mudanças no Clima". Dentre os possíveis termos relacionados com a COP21 em espanhol foram encontradas mais de 12 mil referências ao termo "cumbre clima" (total 12.436), em face de apenas 258 referências a "conferencia del clima" e 212 referências a "cumbre en/de Paris". O termo "cumbre", em português "cúpula" ou "cimeira", remete para uma reunião de altos representantes de governo de vários países. $\mathrm{Na}$ verdade, participam nas COPs delegações oficiais nacionais compostas por funcionários especializados no tema, sendo que os líderes políticos têm apenas uma breve presença. Para além disso, participam nas COPs diversos atores sociais convidados, como cientistas e empresários, e uma grande variedade de outros com o estatuto formal de "observador". A palavra "cúpula" ou "cimeira" sugere que a COP foi frequentemente "reduzida", no debate público em língua espanhola, a um encontro de alto nível, o que pode gerar (ou estar associado) à ideia de que a responsabilidade de encontrar respostas cabe aos chefes de Estado e de governo, uma visão de elite, algo redutora.

Já em português, o termo "conferência do clima" foi o mais citado, chegando quase a 900 vezes e contrastando com "cúpula do clima" que não atingiu nem 150 menções. A diferença é ainda 
maior para o uso dos termos "cimeira do clima", com 31 referências, e "cimeira de Paris" só citada quatro vezes. Isso também se deve ao menor uso do termo "cimeira", mais utilizado no português europeu, proporcionalmente aos termos equivalentes usados no Brasil, "conferência" e "cúpula".

Nota-se que "mudanças climáticas" são, em todos os termos referidos, substituídas por "clima", o que obviamente pode estar relacionado ao espaço disponível para publicações no Twitter, mas pode também trazer mudanças no entendimento do tema.

\subsubsection{Países e nacionalidades}

Percebeu-se na wordlist das 100 palavras mais utilizadas uma tendência de citar os países e lideranças políticas nacionais. $\mathrm{Na}$ investigação sobre a cobertura jornalística das mudanças climáticas, alguns estudos mostram uma tendência para a "domesticação" da questão pela mídia, com um tratamento focalizado nos respectivos países (Eide et al., 2010). Como tal, considerou-se pertinente investigar as referências a países e nacionalidades em todas publicações coletadas. Para isso, foi organizada uma lista de países falantes das línguas espanholas e portuguesa e suas respectivas nacionalidades permitindo que pudessem ser identificadas mais informações dentro da base de dados dos tweets do que as fornecidas pelo geolocalizador ${ }^{9}$, pois a maioria dos utilizadores não o utiliza.

As referências aos países de língua espanhola são menos díspares quantitativamente do que aos de língua portuguesa, apesar de existir mais do que o dobro de países falantes do primeiro idioma. Como demonstrado na Figura 2, a Espanha tem mais de 5 mil referências, seguida pelo Equador e Peru, que, junto de Colômbia e Cuba, são os cinco países que se sobressaem como mais citados. Apenas Guiné Equatorial não foi referida entre os 21 países oficialmente falantes de língua espanhola, mas o país também tem como língua oficial o francês e o português. O Equador ${ }^{10}$, com apenas cerca de 16 milhões de habitantes, destaca-se claramente neste ranking. Do mesmo modo, ressalta-se o caso de Cuba, com apenas 11 milhões de habitantes. Pela relativa ausência, é notório o caso do México, com 120 milhões de habitantes, sendo também de referir a Argentina. A diferença fica ainda mais nítida considerando a adesão às redes sociais, na qual o México é o vice-líder do ranking na América Latina com 49,5 milhões de utilizadores e a Argentina em terceiro lugar com 20 milhões (EMarketer, 2016). ${ }^{11}$

A Figura 3 evidencia as diferenças entre os países de língua espanhola ao mostrar o número de menções aos mesmos por milhão de habitantes. Sobressai claramente o Panamá, para além de Cuba e Equador (já referidos).

$\mathrm{Na}$ análise de menções a nacionalidades os totais encontrados foram relativamente baixos, com destaque para os "peruanos" (279), seguidos por "mexicanos" (164), “colombianos" (129) e "espanhóis" (108).

Quanto aos países de língua portuguesa, como mostrado na Figura 4, claramente as menções ao Brasil têm um volume maior. As referências a Portugal são muito inferiores, mas superiores aos

\footnotetext{
${ }^{9}$ Este artifício é utilizado para informar a localização do @utilizador, latitude e longitude, mas o autor da publicação pode optar por divulgar, ou não, esta informação e, se divulgar, pode ser para toda a rede ou somente a rede de contatos. Embora em rede social seja comum a ação de "check-in", ou seja, anunciar a localização, foram obtidos poucos resultados.

${ }^{10}$ Disponível em: <http://countrymeters.info/>. Acesso em: set. 2016.

${ }^{11}$ Disponível em: <http://www.emarketer.com/Article/Social-Network-Growth-Slows-Latin-America/1014103>. Acesso em: set. 2016.
} 


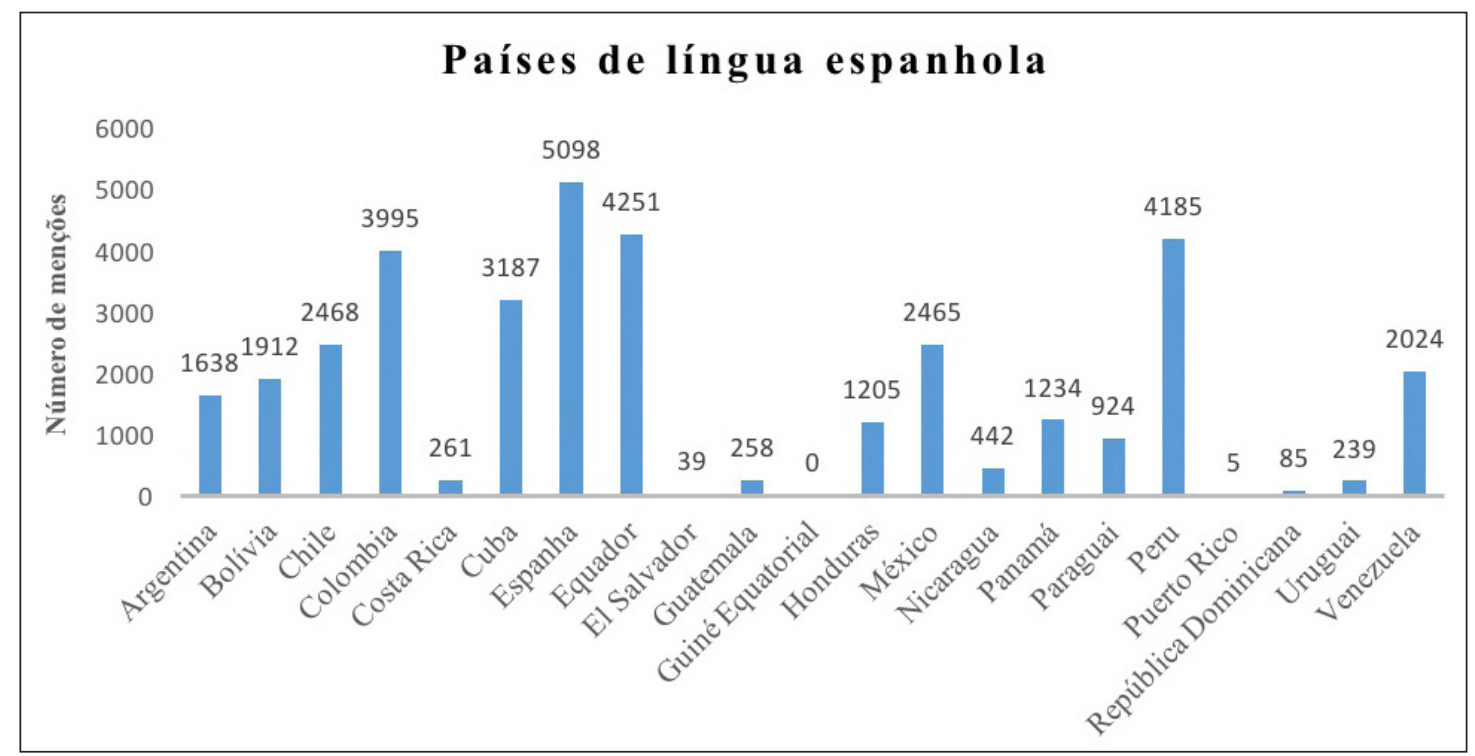

FIGURA 2 -Menções a países de língua espanhola.

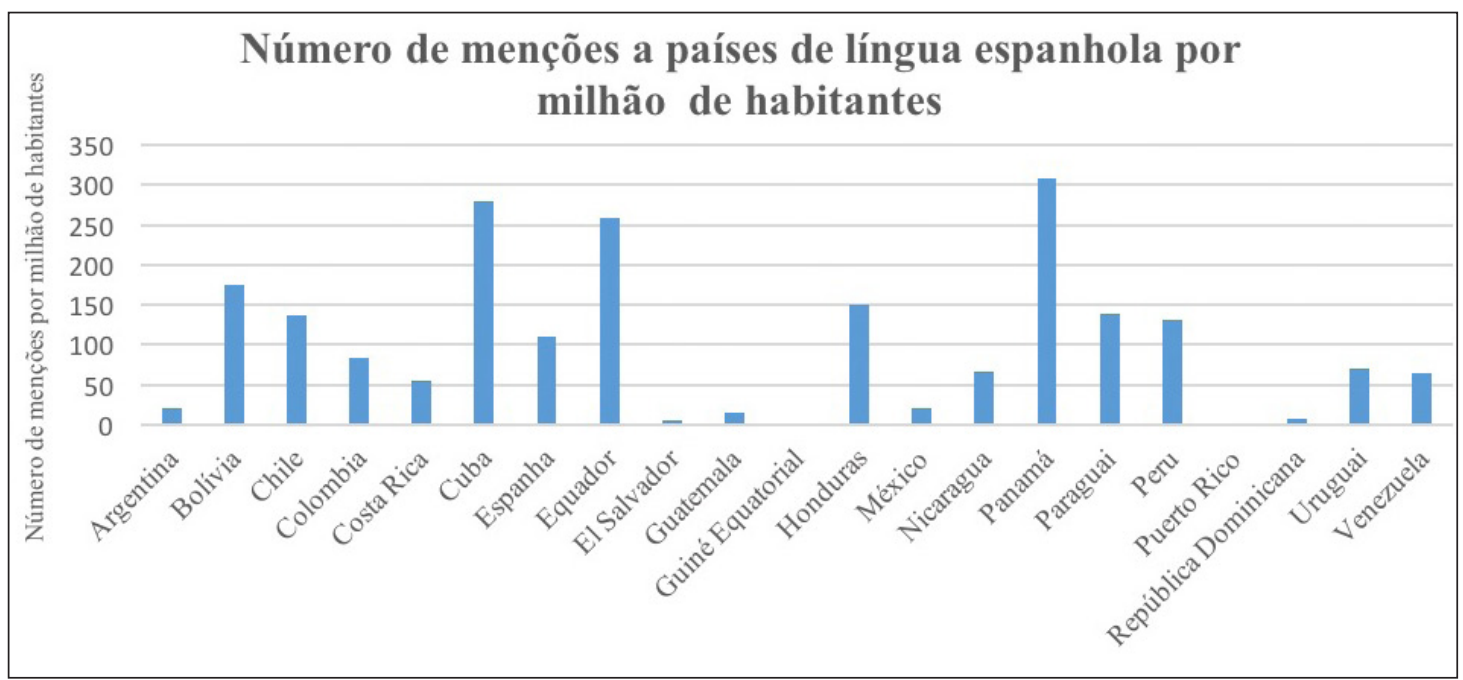

FIGURA 3 -Menções a países de língua espanhola por milhão de habitantes.

demais países - Moçambique, Angola, Guiné-Bissau, Cabo Verde e São Tomé e Príncipe, por ordem decrescente. Não foram encontradas referências a Guiné Equatorial nem Timor Leste. Foram escas- sas as referências às nacionalidades, sendo apenas encontradas referências a dois países entre os nove: somente "brasileiros" - 117 - e "portugueses" - um - foram referidos na amostra. 


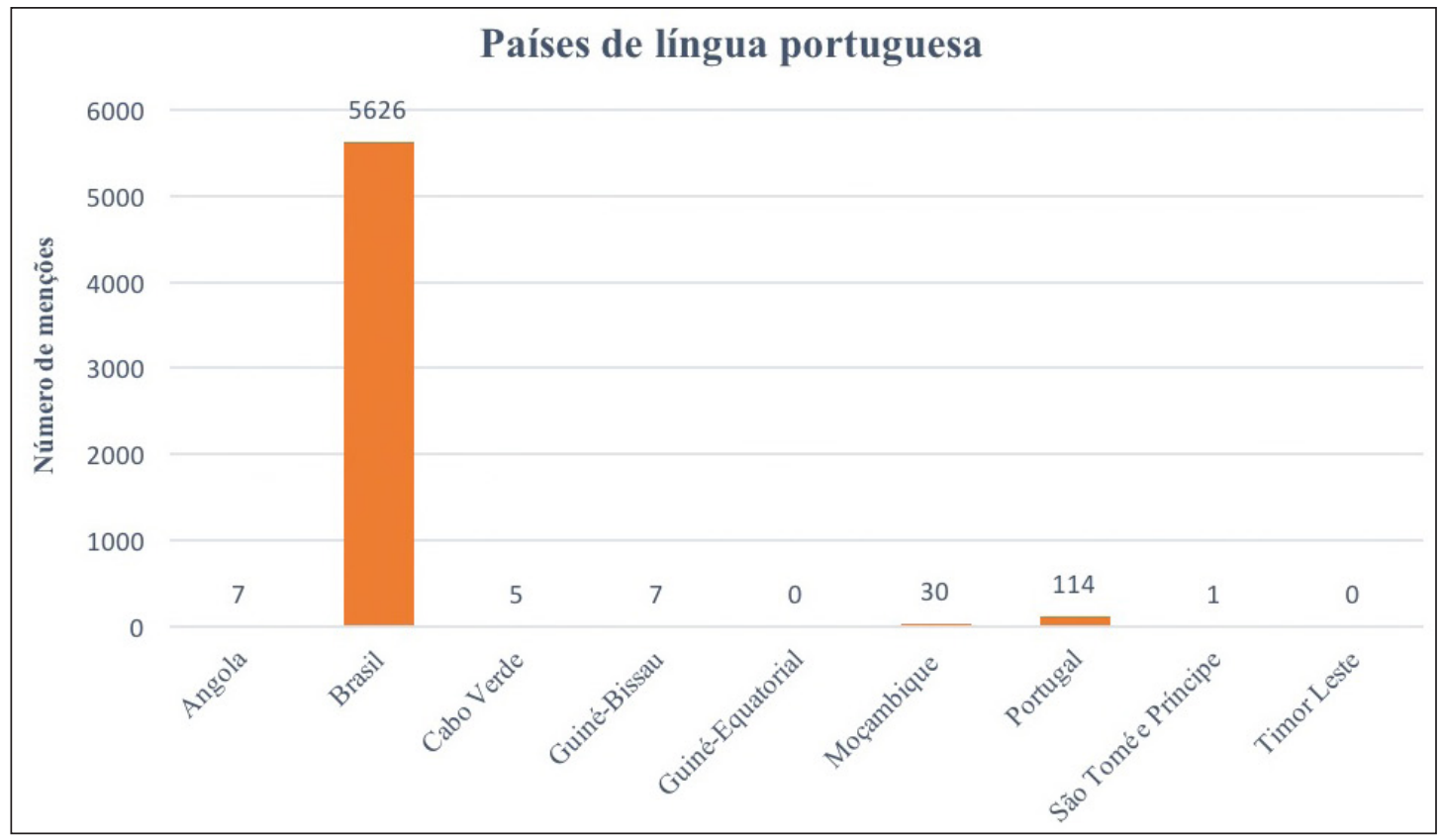

FIGURA 4 - Número de menções a países de língua portuguesa.

Mesmo considerando que se trata do maior país falante da língua portuguesa, com população acima de 200 milhões de habitantes, as referências ao Brasil são proporcionalmente muito superiores às que são feitas a Portugal (cerca de 50 vezes mais referências sendo a população cerca de 20 vezes maior), como mostra a Figura 5. Os dados sugerem assim uma maior participação de brasileiros no debate sobre mudanças climáticas no Twitter. As razões para a diferença relativamente a Portugal permanecem por estudar.

O Brasil é líder no ranking de acessos mensais às redes sociais na América Latina, com 86,5 milhões de utilizadores ativos (EMarketer, 2016). No entanto, apenas 50\% da população do Brasil tem acesso à internet, com índices ainda menores quanto aos domicílios com internet (idem). Portugal fica à frente dos países de língua portuguesa em termos de acesso à internet. Em um estudo do The Net Monitor $^{12}, 64 \%$ da população de Portugal tem acesso à internet e $61 \%$ das residências tem acesso à internet contra 45\% das residências no Brasil. Em Angola, somente $17 \%$ da população tem acesso à internet.

$\mathrm{O}$ número de menções a países no conjunto dos dados é significativo: um total de 35.915 em espanhol, correspondendo a $13,63 \%$ do número total de tweets, e 5.790 em português, que correspondem a $18 \%$ do número total de tweets (massivamente dominado pelo Brasil). Assumindo que em cada tweet não se faz mais do que uma menção a um determinado país, temos que quase um em cada cinco tweets em língua portuguesa faz menção ao

\footnotetext{
${ }^{12}$ Disponível em: <https://thenetmonitor.org/countries/prt/access\#>. Acesso em: set. 2016.
} 


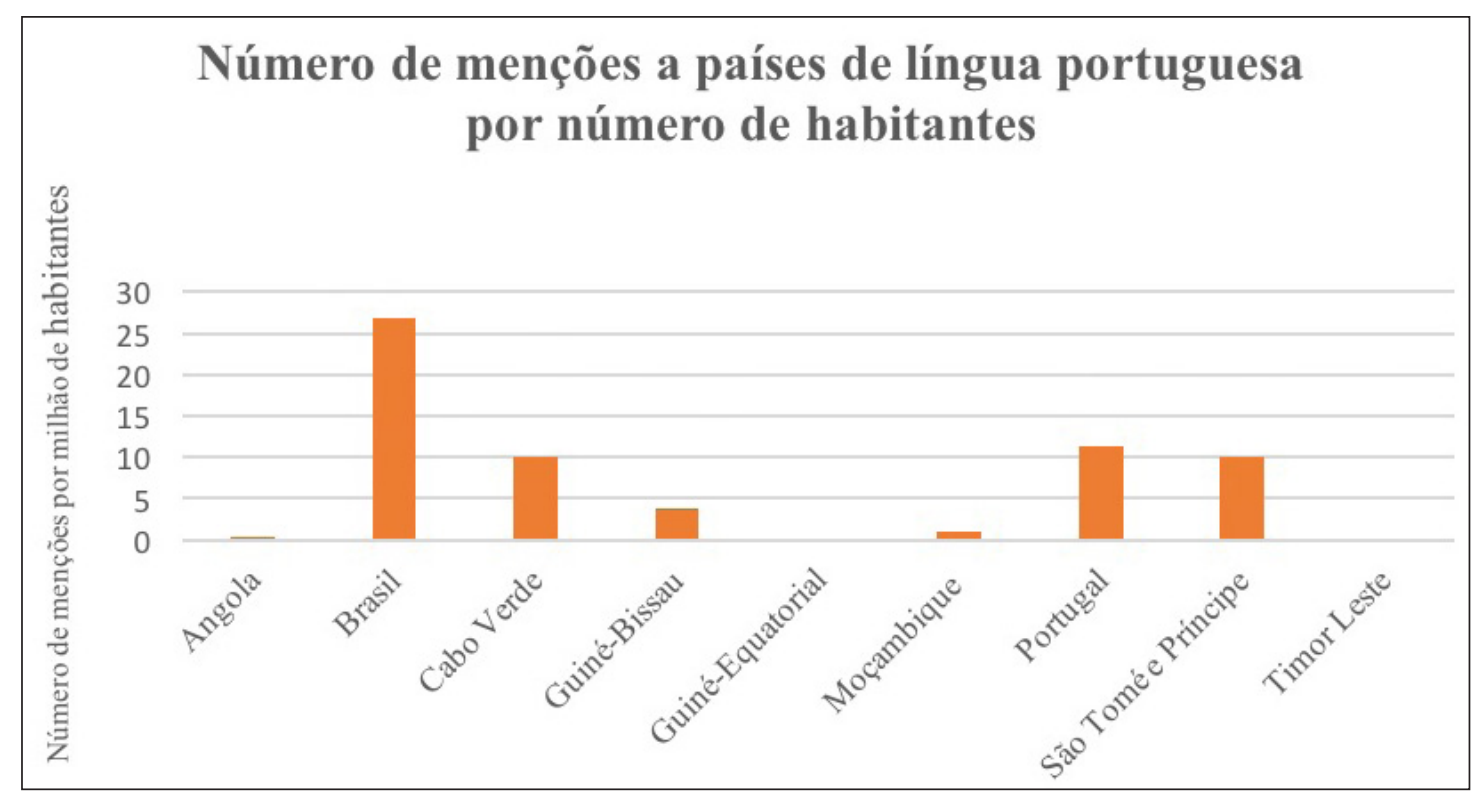

FIGURA 5 -Menções a países de língua portuguesa por milhão de habitantes.

Brasil. Isto pode, porventura, ser interpretado como uma forma de "domesticação" das mudanças climáticas e suas políticas ${ }^{13}$.

\subsubsection{Nível de atividade dos atores sociais}

Foi desenvolvida uma análise dos atores da rede e identificados os perfis mais ativos em cada idioma, que foram categorizados de acordo com a Tabela 1. Em espanhol, a análise revela uma maior intensidade de publicações provenientes da "mídia", seguida pelo "governo e classe política" e "cidadãos" e logo os "grupos cívicos", como representado na Figura 6. Na categoria "mídia" quase metade são portais (47\%), seguidos por veículos de comunicação (19\%) e jornalistas (34\%). Já na categoria "governo e classe política" têm maior representatividade os partidos políticos $(45 \%)$,

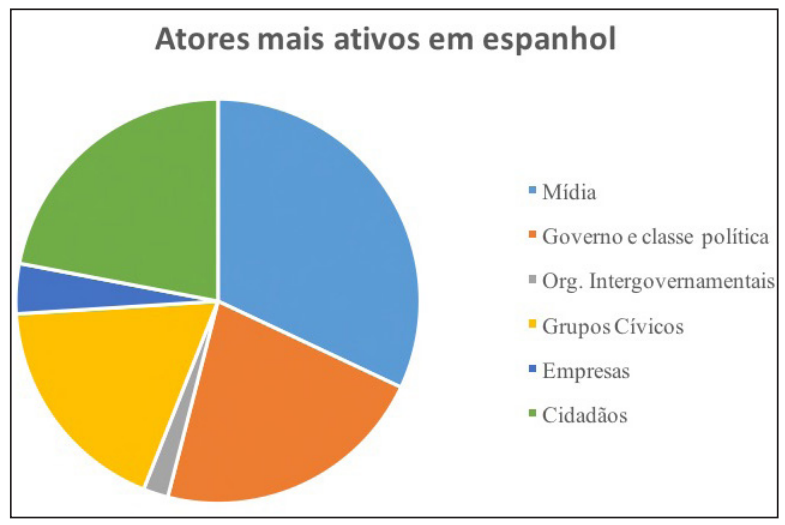

FIGURA 6 -Atores mais ativos (língua espanhola).

\footnotetext{
${ }^{13}$ Naturalmente, os dados apresentados nas Figuras 2-5 não significam que todas as menções a cada país tenham sido escritas por habitantes do mesmo. Tais menções podem, por exemplo, estar relacionadas com ações ou posições assumidas por determinados países na COP21 que tenham captado atenção internacional, sendo, no entanto, provável que a maioria das menções provenha de habitantes de cada país.
} 
seguidos de representantes políticos (32\%) e ainda de página oficiais do governo (23\%). Os "cidadãos" correspondem na maioria a ativistas $(41 \%)$, outros (32\%) e anônimos (27\%).

Em português, os perfis mais ativos pertencem à categoria "cidadãos" (ver Figura 7). Os cidadãos são na maioria anônimos (56\%), seguidos por outros $(23 \%)$ e ativistas (21\%). A segunda categoria com mais peso é a "mídia", composta por portais $(50 \%)$, jornalistas (35\%) e veículos de comunicação (15\%). A seguir aparecem os "grupos cívicos" $(12 \%$ do total de menções) e "governo e classe política" (7\% do total). Na categoria "governo e classe política" não foi encontrado registro de partido político ou integrante de partido, sendo a maioria de páginas oficiais do governo (85\%) e o restante de representantes políticos. O elevado nível de atividade dos cidadãos em português é um achado sociológico de grande interesse.

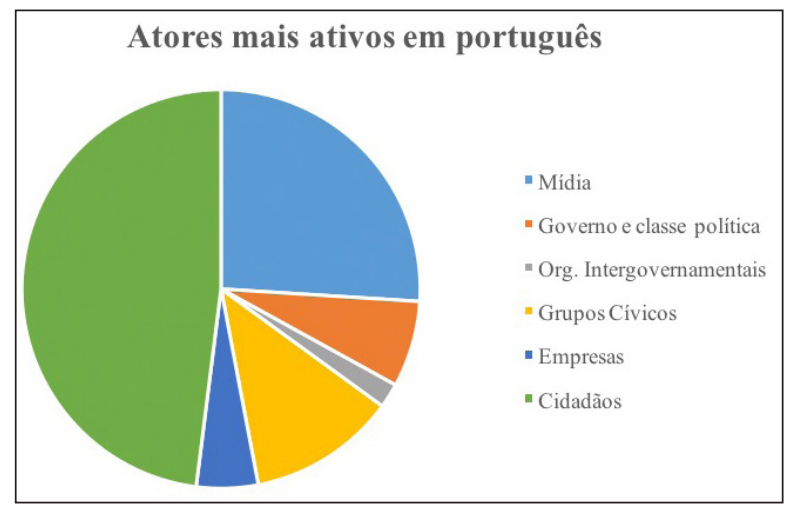

FIGURA 7 -Atores mais ativos (língua portuguesa).

\subsubsection{Influência dos atores sociais}

Entre os perfis mais citados em língua espanhola, destacou-se a categoria "governo e classe política", sendo as referências a representantes políticos (41,5\%), órgãos oficiais do governo (39\%) e partidos políticos (19,5\%), como mostra a Figura 8. Na categoria "mídia" a maioria das referências foi aos veículos de comunicação (44,5\%), seguidos de portais $(33,3 \%)$ e jornalistas $(22,2 \%)$. Os "grupos cívicos" também foram referidos (11\% do total). Na lista dos "cidadãos" destacaram-se os ativistas (54\%) e a subcategoria outros (45\%). Houve ainda citações de "organizações intergovernamentais" ( $7 \%$ do total) e algumas "empresas" ( $3 \%$ do total). Entre os 100 mais citados, nenhum anônimo, empresa ou empresário foi referido.

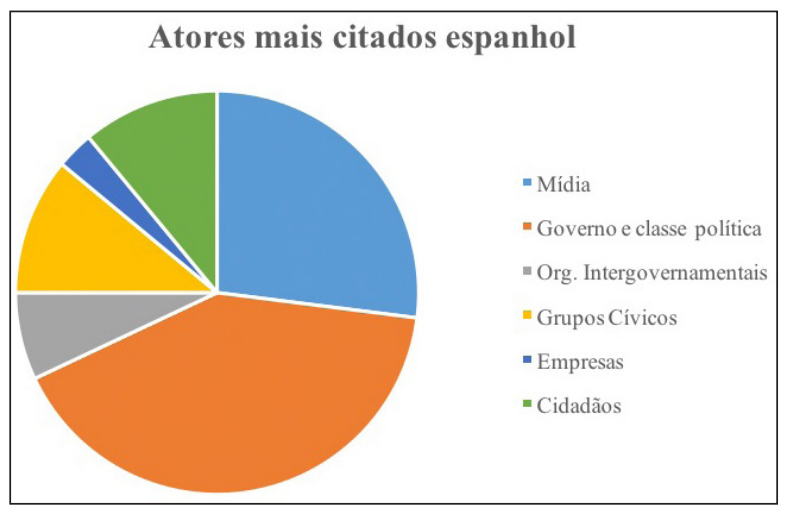

FIGURA 8 - Atores mais citados (língua espanhola).

Entre os mais citados em língua portuguesa o destaque foi para a "mídia", composta em sua maioria por veículos de comunicação (65\%), e ainda jornalistas $(27,5 \%)$ e portais $(7,5 \%)$. Como ilustrado pela Figura 9, surgiram depois os "cidadãos" com outros (46\%), anônimos (29\%) e ativistas (25\%). Seguiu-se o "governo e classe política", tendo as páginas de órgãos oficiais do governo metade de todas as citações $(50 \%)$, à frente de representantes políticos (37,5\%) e de partidos políticos (12,5\%). Os grupos cívicos foram mais citados que as organizações intergovernamentais e somente um empresário foi encontrado entre os mais citados. 


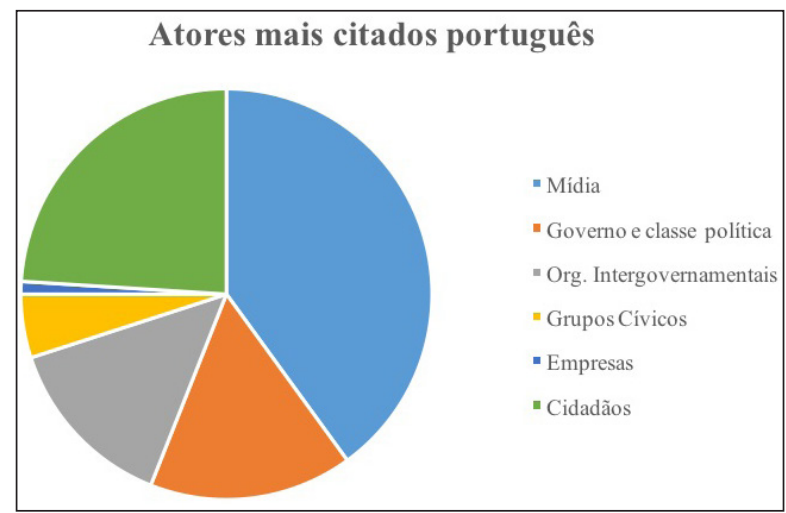

FIGURA 9 - Atores mais citados (língua portuguesa).

\subsubsection{Conectividade (hyperlinks) e recursos visuais}

$\mathrm{Na}$ análise de tipo de conteúdo presente nas publicações verificou-se que entre os 100 tweets mais populares em espanhol analisados a maioria possui link externo. Foram 75 links, sendo que 34 remetiam a fotografias. Dos demais, 17 continham uma fotografia e um link externo para portais (10 da mídia, duas organizações, um blog, três de páginas oficiais da $\mathrm{ONU}$, e ainda uma página de governo). Outros 13 continham link para portais (nove da mídia, três de governo e classe política e uma organização). Além disso, três links remetiam para outros tweets, três eram links de vídeos, três eram links para um aplicativo de vídeo que faz transmissão ao vivo, um GIF $^{14}$ com link para mídia e um GIF contendo informações de agenda (no caso, a programação de um político).

Em português, dos 100 tweets mais populares analisados, 84 possuem link, sendo que 75 remetem para link externo de portais (70 para mídia, três organizações e dois $b \operatorname{logs}$ ). Além disso, são registradas sete fotografias e dois links para tweets. Ou seja, $83 \%$ dos links externos referiam a mídia. Este tipo de partilha corrobora com a caracterização do Twitter como um popular meio de atualização de informações (Kwak et al., 2010).

\subsubsection{Popularidade das publicações}

De modo a realizar uma análise mais detalhada efetuou-se um recorte nas 100 mensagens mais populares, tendo-se analisado as 25 publicações mais populares (ou seja, que mais vezes foram retweetadas/partilhadas) em cada uma das línguas.

$\mathrm{Na}$ amostra em língua espanhola, identificou-se que $60 \%$ dos tweets continham declarações de governantes, presidentes e ex-presidentes, como também governadores de estados e representantes de partidos políticos. Destas 15 mensagens, sete podem ser consideradas de autopromoção, sendo registros em primeira pessoa da participação e valorização de atividades realizadas no evento. Em alguns destes casos foram utilizados artifícios como fotografias do governante entre os demais líderes e em locais com identificação referindo COP21, além de uma publicação com transmissão ao vivo através de um aplicativo de vídeo.

As duas publicações mais populares envolvem campanhas de organizações com reconhecimento mundial: Greenpeace (partilhada 6.867 vezes) e Avaaz ${ }^{15}$ (partilhada 1.318 vezes), respectivamente. O cantor espanhol Alejandro Sanz também aparece no ranking com duas publicações, sendo que uma delas é a mais popular de todas (partilhada 1.073 vezes) provoca os seguidores a exigirem energias

\footnotetext{
${ }^{14} \mathrm{O}$ GIF (Graphics Interchange Format), é um formato digital de imagem.

${ }^{15} \mathrm{https}: / /$ secure.avaaz.org/po/
} 
renováveis e apela pelo compartilhamento da mensagem.

Entre as publicações mais populares em português, cinco são da presidente do Brasil, Dilma Rousseff, que participou da COP21. As mensagens enaltecem a participação do Brasil na construção do Acordo, trazem o relato de uma conversa com o presidente dos Estados Unidos, Barack Obama, sobre as propostas o Acordo, outra sobre a coordenação dos Chefes de Delegação na COP21 e sobre o fato de o Acordo prever o fornecimento de recursos aos países em desenvolvimento oriundos dos países desenvolvidos.

Nas 25 publicações mais populares em língua portuguesa, as referências à mídia são majoritárias. A mídia alcançou também um elevado nível de popularidade nos conteúdos em língua espanhola na rede social no período analisado. Os dados relativos à popularidade da mídia são detalhados a seguir.

\subsection{Twitter como espaço de reprodução do discurso midiático}

As reportagens presentes entre as publicações mais populares em espanhol contextualizam o que são as mudanças climáticas. Uma delas foi publicada na página do Programa Mundial de Alimentos, da ONU, contendo projeções de como será o futuro do planeta, em 2080. Duas outras reportagens abordam o contexto das mudanças climáticas na América Latina, realizadas pela BBC Mundo, sobre como a América Latina é afetada e as razões para se preocupar com as mudanças climáticas. Outra reportagem é realizada pela TeleSur, emissora multi-estatal para América Latina com sede na Venezuela, com enfoque nas falhas do antigo acordo, o protocolo de Kyoto, que completou 18 anos da assinatura e ainda tem compromissos não alcançados. Encontrou-se ainda uma reportagem sobre a poluição no mundo e os riscos enfrentados pela contaminação dos solos e do ar, com dicas do que pode ser feito para preservar o planeta, citando as celebrações de uma comunidade indígena que vive na região dos Andes (localizada entre a Argentina, a Bolívia e o Peru) e celebra a "Pachamama" (língua local para Mãe-Terra).

Em língua portuguesa, apesar do domínio de popularidade da mídia, somente três publicações entre as 25 mais populares são relativas a reportagens explicativas e contextualizadas. As reportagens referem-se a abordagens sobre a Conferência, explicando o que é a COP2 1 com o contexto ambiental e a expectativa sobre o acordo; a polêmica da compensação sobre perdas e danos e as responsabilizações sobre as consequências das mudanças climáticas e emissões de poluentes; e, por fim, sobre o futuro, com as previsões de como o aquecimento global afetará o planeta e os humanos. As demais publicações que têm a mídia como fonte de referência são sobre a cobertura do evento, declarações de governantes e expectativa para a assinatura do Acordo de Paris. O texto destes tweets, em todos os casos, é o título da matéria.

A publicação mais popular é uma matéria do portal da Rede Globo ${ }^{16}$, o G1 ${ }^{17}$, sobre a expectativa para o encerramento da Conferência (partilhada 608 vezes). Já a segunda mais popular de todas é uma campanha organizada pela Avaaz (partilhada 384 vezes) contra o uso de combustíveis fósseis, contendo exatamente o mesmo texto em espanhol,

\footnotetext{
${ }^{16} \mathrm{http}: / /$ redeglobo.globo.com/

${ }^{17} \mathrm{http}: / / \mathrm{g} 1 . \mathrm{globo} . \mathrm{com} /$
} 
que também ficou em segundo lugar no ranking. A publicação ${ }^{18}$ cita a presidente do Brasil, da África do Sul e da China e o primeiro ministro da Índia, referindo que o futuro está nas mãos deles.

\subsection{Twitter como meio de divulgação e promoção política}

Os políticos destacaram-se entre os utilizadores mais citados e as suas declarações entre as mensagens mais populares, constando também nas notícias partilhadas, e estiveram inclusive entre os mais ativos. Viu-se que, entre as mensagens mais populares, a campanha da Avaaz que cita presidentes também foi bastante partilhada na rede social, sendo a segunda mensagem mais "relevante" para os atores da rede nos dois idiomas.

As listas das 100 palavras mais usadas (wordlist) em cada idioma oferece também indicadores importantes sobre o impacto dos líderes políticos na comunicação sobre mudanças climáticas no período estudado, sendo perceptíveis algumas diferenças entre espanhol e português. Na wordlist em espanhol, as organizações intergovernamentais e os governantes ocupam lugares de topo nas referências a pessoas e entidades: ONU (52 $)$, Mashirafael (nome de utilizador do presidente do Equador, 25 ${ }^{\mathrm{a}}$ ) e Precidencia MX (página oficial da presidência do México, $79^{\mathrm{a}}$ ). No entanto, a Greenpeace é a entidade mais referida $\left(11^{\mathrm{a}}\right)$, e a WWF España também consta do top100 $\left(81^{\mathrm{a}}\right)$. Representando a mídia, a Efeverde surge na posição $85^{\mathrm{a}}$. Em português, os líderes políticos e a mídia aparecem ainda mais. Destacam-se na lista líderes como Dilma (presidente do Brasil, $8^{\mathrm{a}}$ ), Dilmabr (nome de utilizadora da presidente do Brasil, 11 $1^{\mathrm{a}}$ ), Obama (presidente USA, 29a) e Hollande (presidente francês, $54^{\mathrm{a}}$ ). A ONU (organização intergovernamental) surge na posição $25^{\text {a }}$. Representantes da mídia no top 100 estão BBC Brasil $\left(80^{\mathrm{a}}\right)$ e UOL ( $82^{\mathrm{a}}$ que é um portal de notícias) e ainda Veja $\left(12^{\mathrm{a}}\right)$ (que pode ser o nome de uma revista brasileira, da editora Abril ${ }^{19}$, como também o verbo "ver").

Ao se tratar de uma amostra coletada durante o período de uma agenda intergovernamental sabia-se que havia a probabilidade de se registrar a participação de governantes. No entanto, descobriu-se que políticos de diferentes instâncias fizeram uso do espaço para divulgar não só o comprometimento do Estado que representam com o Acordo, como também de enaltecer a sua presença no evento e divulgar ações. Verificou-se que a utilização de artifícios como fotografias e vídeos foi também aliada na divulgação da participação de governantes na COP21. Nas fotografias partilhadas é possível ver os políticos em reuniões, na sede da realização da Conferência, encontros entre líderes e, em especial, registros com Ban Ki-moon, atual secretário-geral da Organização das Nações Unidas. Ou seja, muitos mais usaram o Twitter para partilha e divulgação de informações do que para interação com os seguidores (Amaral et al., 2016). A identificação de páginas oficiais também reforça esta conclusão.

Entre as mensagens mais populares em espanhol destaca-se a participação ativa do governador do estado de Jalisco do México (Aristóteles Sandoval), com $24 \%$ das publicações das 25 mensagens analisadas. Foram registradas publicações de somente dois presidentes de nações (Equador e México) e um ex-presidente (Felipe Calderón, me-

\footnotetext{
${ }^{18}$ Texto do tweet: “Falta pouco para a \#COP21 acabar. Nosso futuro está em suas mãos@dilmabr \#Jiping@narendramodi@SAPresident”com o link: https://secure.avaaz.org/po/climate_story_loc/

${ }^{19} \mathrm{http}: / /$ veja.abril.com.br/
} 
xicano), que juntos somam o número de publicações do governador, além de um candidato a presidente da Espanha (Sanchéz, PSOE), que é secretário-geral do partido político e deputado por Madrid. As referências a políticos no idioma português remetem mais ao contexto da Conferência e do Brasil. Como já referido, entre as 25 publicações mais populares cinco são do perfil da presidente do Brasil, Dilma Rousseff. As demais menções referem-se à publicação de notícias da cobertura do evento com declarações de governantes. Os textos dos tweets têm as declarações, na maioria dos casos, entre aspas.

Destacaram-se as declarações da Ministra do Meio Ambiente do Brasil, do presidente da COP21, presidente da França e também da presidente do Brasil. Registrou-se também uma declaração de um governador de um estado brasileiro (Acre) na COP21, que apesar de ser um dos menores do país e ter baixa densidade demográfica, está localizado na fronteira com a Bolívia e Peru, abrigando a floresta amazônica, e assumiu o compromisso de combater o desmatamento. No mesmo sentido que os dados analisados neste estudo, D’Essen (2010) tinha já identificado um importante impacto estratégico da política na mídia brasileira durante a COP15 (Copenhague, 2009).

\section{Considerações finais}

A revisão de literatura mostra que o interesse pela pesquisa em redes sociais vem crescendo, embora tenda a centrar-se em conteúdos em língua inglesa. Este estudo procura analisar outros contextos linguístico-culturais, nomeadamente o espanhol e o português.

A diferença no volume de material coletado nos dois idiomas é expressiva, com um claro predomínio do espanhol, quando se sabe que o número de utilizadores falantes do idioma português também é elevado nas redes sociais. A maior atividade de falantes do idioma espanhol pode indicar um maior envolvimento com as questões relacionadas à comunicação das mudanças climáticas, além da valorização da língua para participar na rede.

As variações no volume de publicação ao longo da COP21 acompanharam as variações identificadas na cobertura midiática, principalmente na América Latina (Nivela, 2016). Embora se tenha identificado uma aproximação ocasional ao local (como no caso dos tweets relativos às reportagens sobre as consequências das mudanças climáticas para a América Latina), grande parte das notícias popularmente difundidas envolve a cobertura da Conferência e refere-se ao contexto global, sugerindo um importante impacto da agenda intergovernamental na rede social, como identificado noutros estudos (e.g. Kirilenko \& Stepchenkova, 2014).

Este estudo identificou uma forte expressão dos países na comunicação sobre a COP21 no Twitter, o que pode eventualmente ser interpretado como uma forma de "domesticação" da comunicação sobre mudanças climáticas. Kunelius \& Eide (2012, p. 280) referem que a "domesticação" na mídia tradicional pode ter dois significados. Por um lado, pode prender-se com a tendência do jornalismo para destacar (excessivamente) os atores e posições do país na cobertura de questões globais (por exemplo, enfatizando o impacto internacional do próprio país). Por outro lado, o enfoque no país pode resultar de reflexividade ou monitorização crítica dos atores nacionais. O significado da "domesticação" da política das mudanças climáticas no Twitter será uma questão de interesse a explorar futuramente. $\mathrm{O}$ caso do Brasil será particularmente interessante porque vários estudos concluem que a imprensa nacional se centra sobretudo na dimensão global/internacional das mudanças climáticas e usa 
uma proporção de fontes/vozes estrangeiras especialmente elevada (e.g. Kunelius \& Eide, 2012). Diferenças e semelhanças entre discursos da mídia tradicional e discursos no Twitter serão, portanto, de investigar.

Identificou-se a preferência pelo uso de hashtags na maioria dos tweets, reforçando a ideia de que os utilizadores querem fazer parte de "comunidades". O grande volume de links encontrados reforça a ideia de que o Twitter é bastante usado para partilha e atualização de informação (Recuero, 2009; Veltri \& Atasanova, 2015).

Não foram encontradas referências negacionistas das mudanças climáticas em nenhum dos idiomas entre as mensagens mais populares analisadas, mesmo dentro do contexto da realização da Conferência. Também se identificou um consenso sobre as mudanças climáticas na abordagem midiática partilhada no Twitter, ainda que haja exemplos que se referem às mudanças climáticas como uma hipótese. A maioria das abordagens envolveu as consequências para o futuro. No contexto da COP, os conteúdos mais populares atribuíam expectativas de esperança de um acordo global.

Entre os utilizadores do Twitter mais ativos em espanhol a mídia predominou, mas as diferenças são pequenas entre governo e classe política, cidadãos e grupos cívicos. Em português os cidadãos apresentaram atividade acentuada, sendo o grupo mais ativo, seguidos pela mídia, e algumas parcelas de grupos cívicos e governo e classe política. Quando consideradas as citações a atores da rede percebe-se o predomínio, em espanhol, do governo e classe política, seguido pela mídia. Em português, a mídia é a categoria dominante nos mais citados, seguida pelos cidadãos, governo e classe política, e organizações intergovernamentais. A influência da mídia no Twitter, em especial em português, é evidente, sendo consistente com dados em língua inglesa (e.g.Williams et al., 2015), e sugere que o Twitter funciona como um espaço de reprodução do discurso midiático. Já em espanhol, a influência do governo e classe política é considerável, até porque essa não é a primeira categoria em termos de atividade, o que denota, entre os falantes de espanhol, uma forte atenção ao governo e à classe política, nomeadamente determinadas figuras políticas individuais.

No Twitter, líderes de opinião continuam a ser importantes para o discurso sobre as mudanças climáticas, como referem Kirilenko \& Stepchenkova (2014). No contexto estudado aqui, em que se aborda a assinatura de um acordo climático global, muitos dos tweets mais partilhados e dos perfis mais citados são de governantes. Os líderes políticos destacaram-se em várias instâncias em espanhol e em português, particularmente a presidente do Brasil, Dilma Rousseff. No entanto, também se destacaram publicações de organizações não-governamentais mundialmente conhecidas, como Greenpeace e Avaaz, e celebridades, como o cantor Alejandro Sanz, que é uma figura pública com diversos fãs e referência entre as mensagens mais populares.

A forte presença de utilizadores representando entidades governamentais/políticas e a mídia pode sugerir que, no contexto da realização da COP21, os cidadãos utilizadores da rede social Twitter possam ter sido constituídos mais como espectadores do que participantes das discussões e reuniões entre políticos e cientistas (Carvalho, 2010). A grande propagação de declarações políticas reforça a ideia de que a política das mudanças climáticas é reservada aos líderes. Pessoas que fazem parte de partidos políticos, que se consideram ativistas políticos, e membros de governo das mais diferentes instâncias, como foram identificados - ou seja, que já estão envolvidos no processo político - são mais propensas a utilizar as redes sociais para divulgar 
ações políticas do que o "cidadão comum" (Bekafigo \& McBride, 2013). No entanto, nos dados em português, se analisada a atividade no Twitter, a clara prevalência dos cidadãos na comunicação sobre a COP21 é assinalável e sugere um nível de engajamento muito significativo, contrariando outros sinais e indicadores. Se somados aos grupos cívicos, temos que as publicações de membros da sociedade civil correspondem a bem mais de metade de toda a atividade na rede. Não se encontraram indicações, entre os tweets analisados, de que esta rede tenha sido utilizada para organizar ações cívicas relacionadas com as mudanças climáticas, mas a confirmação desta tendência carece de uma análise mais alargada.

\section{Referências}

Amaral, I.; Zamora, R.; Grandío, M., Noguera, J. M. Flows of communication and 'influentials' in Twitter: A comparative approach between Portugal and Spain during 2014 European Elections. Observatorio $\left(O B S^{*}\right), 10(2), 2016$. doi: 10.7458/obs 1022016900

Auer, M. R.; Zhang, Y.; Lee, P. The potential of microblogs for the study of public perceptions of climate change. Wiley Interdisciplinary Reviews: Climate Change, 5(3), 291-296, 2014. doi: 10.1007/978-3-642-21064-8_26

Bekafigo, M. A.; McBride, A. Who Tweets About Politics? Political Participation of Twitter Users During the 2011 Gubernatorial Elections. Social Science Computer Review, 31, 625-643, 2013. doi: 10.1177/0894439313490405

Boyd, D.; Golder, S.; Lotan, G. Tweet, tweet, retweet: Conversational aspects of retweeting on Twitter. System Sciences (HICSS), 43rd Hawaii International Conference on. IEEE, 2010. doi: 10.1109/HICSS.2010.412

Brown, A.; Wake, B. Public Perception: A Twitter thermometer. Nature Climate Change, 5(2), 98-98, 2015. doi: 10.1038/nclimate2519
Investigações futuras devem envolver a análise da comunicação sobre mudanças climáticas nas redes sociais nas duas línguas estudadas aqui para além do período de agendas internacionais e rotinas políticas.

\section{Agradecimentos}

Este artigo foi elaborado no contexto de projeto do Programa Doutoral em Ciências da Comunicação financiado pela Fundação Coordenação de Aperfeiçoamento de Pessoal de Nível Superior - CAPES (BEX 0404/14-4). O artigo contou com a colaboração de Mariola Norte na utilização da ferramenta AntConc.

Brüggemann, M. (Ed.). Media Representations of Climate. Climate Matters, 2015.

Carvalho, A. Media(ted) Discourses and Climate Change: A Focus on Political Subjectivity and (Dis)engagement. Wiley Interdisciplinary Reviews: Climate Change, 1, 172-179, 2010. doi: 10.1002/wcc. 13

Cha, M.; Haddadi, H.; Benevenuto, F.; Gummadi, P. K. Measuring User Influence in Twitter: The Million Follower Fallacy. ICWSM - Association for the Advancement of Artificial Intelligence, 10(30), 10-17, 2010. doi: 10.1.1.167.192

CJR - Columbia Journalism Review. At the Paris climate talks, media coverage takes a turn, 2015. Disponível em: $<$ https://www.cjr.org/analysis/paris_climate_talks_kick_ off_on_somber_note.php>. Acesso em: jan. 2016.

Cody, E. M.; Reagan, A. J.; Mitchell, L.; Dodds, P. S.; Danforth, C. M. Climate change sentiment on twitter: an unsolicited public opinion poll. PloS ONE, 10(8), 2015. doi: 10.1371/journal.pone.0136092

D'Essen, C. COP15 as a political platform. In: Eide, E, Kunelius, R.; Kumpu, V. (Eds.). Global climate, local jour- 
nalism: A transnational study of how media make sense of climate summits. Bochum, Germany: ProjektVerlag, 2010.

Eide, E.; Kunelius, R.; Kumpu, V. (Eds.). Global climate, local journalism: A transnational study of how media make sense of climate summits. Bochum, Germany: ProjektVerlag, 2010.

EMarketer. Social Network Growth Slows in Latin America, 2016. Disponível em: <https://www.emarketer.com/Article/ Social-Network-Growth-Slows-Latin-America/1014103>. Acesso em: set. 2016

Hajibagheri, A.; Sukthankar, G. Political polarization over global warming: analyzing twitter data on climate change. ASE@360 Open Scientific Digital Library - ASE BIGDATA/SOCIALCOM/CYBERSECURITY Conference, Stanford University, May 27-31, 2014.

Hansen, L. K.; Arvidsson, A.; Nielsen, F. Å.; Colleoni, E.; Etter, M. Good friends, bad news-affect and virality in twitter. In: Hunsinger, J.; Klastrup, L.; Allen, M. M. (Eds.). International Handbook of Internet Research, 2011. p. 233-249. Springer Netherlands. doi: 10.1007/978-1-40209789-8_14

Herring, S. C. Web Content Analysis: Expanding the Paradigm. In: Hunsinger, J.; Klastrup, L.; Allen, M. M. International Handbook of Internet Research. Amsterdam: Springer Netherlands - Springer Science+Business Media, 2009. p. 233-249. doi: 10.1007/978-1-4020-9789-8_14

Kirilenko, A. P.; Molodtsova, T.; Stepchenkova, S. O. People as sensors: Mass media and local temperature influence climate change discussion on Twitter. Global Environmental Change, 30, 92-100, 2015. doi: 10.1016/j. gloenvcha.2014.11.003

Kirilenko, A. P.; Stepchenkova, S. O. Public microblogging on climate change: One year of Twitter worldwide. Global Environmental Change, 26, 171-182, 2014. doi: 10.1016/j. gloenvcha.2014.02.008

Kunelius, R.; Eide, E. Moment of hope, mode of realism: On the dynamics of a transnational journalistic field during UN climate change summits. International Journal of Communication, 6, 266-285, 2012.

Kwak, H.; Lee, C.; Park, H.; Moon, S. What is Twitter, a social network or a news media? In: Proceedings of the 19th International Conference on World Wide Web. ACM, p. 591-600, Abril, 2010. ACM. doi: 10.1145/1772690.1772751
Merry, M. K. Broadcast Versus Interaction: Environmental Groups' Use of Twitter. Journal of Information Technology \& Politics, 11, 329-344, 2014. doi: 10.1080/19331681.2014.933723

Nivela - COP21: media coverage in Latin America. 2016. Disponível em: $<$ http://www.nivela.org/articles/cop21-cobertura-en-medios-de-latinoamerica/en $>$. Acesso em: set. 2016.

O’Neill, S.; Boykoff, M. The role of new media in engaging the public with climate change. In: Whitmarsh, L.; Lorenzoni, I.; O'Neill, S. (Eds.). Engaging the public with climate change: behaviour change and communication, 2011. p. 233-251.

Pearce, W.; Holmberg, K.; Hellsten, I.; Nerlich, B. Climate change on Twitter: Topics, communities and conversations about the 2013 IPCC Working Group 1 report. PloS ONE, 9(4), 2014. doi: 10.1371/journal.pone.0094785

Recuero, R. Redes sociais na internet, difusão de informação e jornalismo: elementos para discussão. In: Soster, D. A.; Firmino, F. (Eds.). Metamorfoses Jornalísticas 2: a reconfiguração da forma. Santa Cruz do Sul - Brasil: UNISC, 2009. p. 37-55.

Rudat, A.; Buder, J.; Hesse, F. W. Audience Design in Twitter: Retweeting Behavior between Informational Value and Followers' Interests. Computers in Human Behavior, 35, 132-139, 2014. doi: 10.1016/j.chb.2014.03.006

Schäfer, M. S.; Schlichting, I. Media Representations of Climate Change: A Meta-Analysis of the Research Field. Environmental Communication, 8(2), 142-160, 2014. doi: $10.1080 / 17524032.2014 .914050$

Segerberg, A.; Bennett, W. L. Social Media and the Organization of Collective Action: Using Twitter to Explore the Ecologies of Two Climate Change Protests. The Communication Review, 14, 197-215, 2011. doi: 10.1080/10714421.2011.597250

Takahashi, B.; Edwards, G.; Roberts, J. T.; Duan, R. Exploring the Use of Online Platforms for Climate Change Policy and Public Engagement by NGOs in Latin America. Environmental Communication, 9(2), 228-247, 2015. doi: 10.1080/17524032.2014.1001764

The Net Monitor - Internet Monitor - Countries. Disponível em: $<$ https://thenetmonitor.org/>. Acesso em: set. 2016. 
Theocharis, Y.; Lowe, W.; van Deth, J. W.; García-Albacete, G. Using Twitter to mobilize protest action: online mobilization patterns and action repertoires in the Occupy Wall Street, Indignados, and Aganaktismenoi movements. Information, Communication \& Society, 18(2), 202-220, 2014. doi: 10.1080/1369118X.2014.948035

Veltri, G.; Atasanova, D. Climate change on Twitter: Content, media ecology and information sharing behaviour. Public Understanding of Science, 2015. doi: 10.1177/0963662515613702
Whitmarsh, L. What's in a Name? Commonalities and Differences in Public Understanding Of "climate Change" and "global Warming"". Public Understanding of Science, 18(4), 401-420, 2009. doi: 10.1177/0963662506073088

Williams, H. T.; McMurray, J. R.; Kurz, T.; Lambert, F. H. Network analysis reveals open forums and echo chambers in social media discussions of climate change. Global Environmental Change, 32, 126-138, 2015. doi: 10.1016/j. gloenvcha.2015.03.006 